\title{
Luas Pengungkapan Tata Kelola Perusahaan pada Bank Syariah di Indonesia
}

\author{
Rizki Amalia Elfita, Heni Agustina \\ Universitas Nahdlatul Ulama Surabaya \\ e-mail: elfita@unusa.ac.id
}

\begin{abstract}
The purpose of this study is to empirically test the influence of the size of Islamic banks, Muslim board of director proportion, and sharia supervisory boards on the broad disclosure of corporate governance. The population in this research is a sharia banking company in Indonesia in 2015 to 2018 with a total of 44 company data. The sample was selected using a purposive sampling method. The data used in this study were analyzed using multiple linear regression analysis. Multiple linear regression analysis was carried out with the help of SPSS 25.0 software. The results of the study showed that there were 41 data samples of sharia bank companies in Indonesia that met the criteria of purposive sampling which assigned in this research. The results of this research prove that the size of Islamic banks, Muslim board of director proportion, and sharia supervisory boards were positively influenced the broad disclosure of corporate governance.
\end{abstract}

Keywords: size of Islamic banks, Muslim board of director proportion, sharia supervisory board, corporate governance disclosures

\section{PENDAHULUAN}

Ketidakpastian ekonomi secara global terjadi pada industri dalam beberapa tahun terakhir menyebabkan peningkatan terhadap risiko yang dapat dihadapi oleh perusahaan salah satunya yakni fluktuasi harga bahan baku yang menyebabkan perusahaan kesulitan memproyeksikan laba di masa depan. Salah satu perusahaan yang menghadapi tingkat risiko besar akibat ketidakpastian ekonomi adalah perusahaan perbankan. Perusahaan perbankan merupakan satu perusahaan yang menghadapi tingkat risiko yang paling besar (Abdullah dkk., 2015). Perusahaan perbankan juga menghadapi risiko sistemik, yakni risiko yang timbul karena kegagalan dalam satu perusahaan perbankan yang dapat memberikan dampak terhadap perusahaan perbankan lainnya (Abdullah dkk., 2015). Oleh sebab itu, keterbukaan informasi penting untuk dilakukan oleh manajemen dalam kondisi ketidakpastian ekonomi global agar perusahaan tetap dapat menjamin kepercayaan yang diberikan oleh pemegang saham akan kemampuan manajemen dalam mengelola perusahaan (Abdullah dkk., 2015).

Bank syariah merupakan salah satu entitas bisnis yang menerapkan nilai-nilai Islam yang menekankan pada aspek transparansi, moralitas, dan keadilan sosial pada operasional perusahaan (Albassam dan Ntim, 2017). Hal itu disebabkan bank syariah merupakan satu entitas ekonomi yang dapat memberikan dampak secara langsung kepada masyarakat. Sebagai konsekuensinya, implikasi komitmen terhadap prinsip tersebut tecermin dalam tata kelola perusahaan (Safieddine, 2009; Vinnicombe, 2010).

Usaha yang dilakukan manajemen bank syariah dalam mengungkapkan tata kelola perusahaan dapat dipengaruhi oleh faktor internal dalam bank syariah (Adams, 2002). Faktor internal yang mendorong bank syariah untuk melakukan pengungkapan tata kelola perusahaan secara lebih luas antara lain ukuran bank syariah, dewan 
pengawas syariah, dan dewan direksi Muslim (Abdullah dkk., 2015; Baydoun dkk., 1999; Farook dkk., 2011).

Penelitian mengenai pengaruh ukuran perusahaan, dewan direksi Muslim dan dewan pengawas syariah telah dilakukan oleh beberapa peneliti, namun masih terdapat perbedaan hasil antara peneliti satu dengan peneliti lainnya. Dengan ruang lingkup sedemikian rupa maka tujuan penelitian ini adalah untuk mengetahui bagaimana luas pengungkapan tata kelola perusahaan pada bank syariah dipengaruhi oleh ukuran bank syariah, proporsi dewan direksi Muslim, dan jumlah dewan pengawas syariah.

\section{LANDASAN TEORI}

\section{Agency Theory}

Jensen dan Meckling (1976) mengemukakan teori agensi yang menyatakan bahwa pihak agen belum tentu bertindak sesuai kepentingan dari pihak principal yang dapat memicu timbulnya masalah keagenan. Dalam penelitian ini teori agensi menjadi dasar teori untuk menjawab permasalahan terkait dengan tata kelola perusahaan. Dalam tata kelola perusahaan masalah keagenan dapat timbul karena adanya dominasi dari salah satu pihak untuk mencapai kepentingan dirinya sendiri sehingga dapat menimbulkan konflik ketika beberapa kepentingan dari masing-masing pihak saling bertemu dalam suatu aktivitas bersama-sama. Adanya konflik kepentingan antara prinsipal dan agen karena perbedaan tujuan mendorong terjadinya asimetri informasi.

Untuk meredam perbedaan kepentingan antara pihak prinsipal dan agen maka manajemen puncak akan berusaha mengambil keputusan terbaik demi melindungi kepentingan pemegang saham, terutama apabila terdapat keterlibatan oportunis (Jensen dan Meckling, 1976). Teori agensi menjadi salah satu jawaban untuk meminimalkan oportunis manajerial dalam kaitannya dengan usaha perusahaan dalam meminimalkan biaya agensi melalui tata kelola perusahaan (Haniffa dan Hudaib, 2006). Teori agensi juga memfokuskan perusahaan agar dapat mengembangkan struktur tata kelola perusahaan yang baik dengan cara membentuk kontrak hukum oleh pemegang saham yang dapat menjadi suatu alat dalam mengawasi kinerja manajemen.

Kesimpulan yang dapat ditarik dari teori agensi yakni bahwa tata kelola perusahaan yang baik dapat diciptakan melalui pengembangan mekanisme tata kelola perusahaan yang efektif agar dapat menurunkan biaya agensi. Fama dan Jensen (1983) mengungkapkan bahwa perlu adanya perbaikan menyeluruh dari praktik tata kelola perusahaan termasuk untuk kinerja keuangan dan pengungkapan tata kelola perusahaan dengan cara pengurangan biaya pemantauan dan pengikatan. Perbaikan menggambarkan adanya usaha untuk menyelaraskan kepentingan prinsipal dan agen serta kontrol atas organisasi yang diukur melalui kinerja yang lebih baik, oleh sebab itu diperlukan adanya transparansi dari pihak manajemen perusahaan dalam mengungkapkan seluruh informasi terkait kegiatan operasional perusahaan secara menyeluruh agar tidak terjadi masalah agensi (Safieddine, 2009).

Dalam hal ini, manajer dan dewan pengawas bank syariah harus memastikan bahwa kegiatan bisnis yang dilakukan di bank syariah telah sesuai dengan syariah atau nilai-nilai Islam, serta memastikan bahwa kesenjangan informasi dalam laporan keuangan perusahaan dapat diminimalisasi dan terciptanya rasa keadilan bagi semua pihak yang terkait dengan perusahaan (Archer dkk., 2010; Safieddine, 2009; \& Sarker, 1999). Perbankan syariah harus mengedepankan nilai-nilai Islam, di mana dalam nilai-nilai Islam diajarkan mengenai prinsip 
transparansi, keadilan, dan tanggung jawab, oleh karena itu pada perbankan syariah pengungkapan seluruh aktivitas oleh manajemen perusahaan menjadi penting sehingga bentuk laporan tata kelola perusahaan menjadi luas (Albassam dan Ntim, 2017).

\section{Pengungkapan Tata Kelola Perusahaan}

Hassan dan Christopher (2005) berpendapat bahwa tata kelola perusahaan menjadi salah satu perhatian utama dari seluruh perusahaan, terutama untuk perusahaan publik. Pengungkapan tata kelola perusahaan menjadi sarana bagi perusahaan untuk mengungkapkan informasi secara transparan kepada pihak-pihak berkepentingan (Solomon dan Solomon, 2006). Tujuan dari tata kelola perusahaan adalah untuk meningkatkan pengungkapan perusahaan berkaitan informasi mengenai akuntabilitas dan transparansi perusahaan (Allegrini dan Greco, 2013). Pengungkapan tata kelola perusahaan pada bank syariah mengacu pada tingkat pengungkapan tata kelola perusahaan berdasarkan sejumlah tolok ukur tata kelola perusahaan internasional yang diungkapkan dalam Organisation for Economic Co-operation and Development's (OECD) (2014), laporan Komite Basel tentang Pengawasan Bank (Basel Committee on Bank Supervision - BCBS) (2006), dan Standar Tata Kelola AAOIFI untuk Lembaga Keuangan Islam (Abdullah dkk., 2015).

Botosan (1997) menyatakan bahwa laporan tahunan perusahaan merupakan salah satu media utama bagi perusahaan dalam menyampaikan informasi yang berkaitan dengan kondisi keuangan maupun kondisi non-keuangan dari perusahaan. Dengan melakukan pengungkapan informasi secara maksimal maka perusahaan dapat menghasilkan informasi penting yang berkualitas bagi para pihak berkepentingan (O'Sullivan, 2005).

\section{Ukuran Bank Syariah}

Mohamad dan Saeed (2018) menyatakan bahwa ukuran bank syariah dapat ditinjau dari besar nilai aset yang dimiliki oleh bank syariah atau besar kredit yang dapat disalurkan oleh bank syariah. Bank syariah dengan nilai aset yang besar memiliki kemungkinan untuk memberikan berbagai macam layanan keuangan dengan biaya yang lebih rendah (Mohamad dan Saeed, 2018). Besarnya nilai aset yang dimiliki bank syariah juga dapat meningkatkan timbulnya risiko terkait proses pengendalian yang harus dijalankan bank syariah, sehingga diperlukan adanya tata kelola yang baik agar risiko yang timbul terkait dengan proses pengendalian dapat direduksi.

Semakin besar ukuran bank syariah maka akan lebih ketat pengawasan yang dilakukan oleh lembaga pemerintah terkait (Buzby, 1975). Berkaitan dengan hal tersebut, maka bank syariah diharapkan mampu mengungkapkan informasi yang baik dan tepercaya melalui laporan tata kelola perusahaan untuk meminimalisasi tekanan yang ada dari lembaga-lembaga pemerintah (Abdullah dkk., 2015).

\section{Dewan Direksi Muslim}

Beekun dan Badawi (1999) menjelaskan bahwa dewan direksi Muslim adalah anggota dalam jajaran direksi dari manajemen perusahaan yang memeluk agama Islam. Pada umumnya pola kepemimpinan dewan direksi dapat memengaruhi kinerja manajemen dalam suatu perusahaan. Baydoun dkk. (1999) mengungkapkan bahwa perilaku dan pola kepemimpinan dapat dipengaruhi oleh berbagai faktor dan salah satunya adalah faktor agama yang dapat berpengaruh pada fungsi manajemen suatu perusahaan. Dijelaskan lebih lanjut bahwa dewan direksi Muslim, memiliki pengaruh agama Islam lebih me- 
nonjol dalam praktik manajemen bank syariah (Baydoun dkk., 1999). Dewan direksi Muslim diharapkan mampu mengimplementasikan nilainilai Islam dalam kegiatan operasional bank syariah sesuai dengan prinsip-prinsip transaksi dalam perbankan syariah untuk meningkatkan kualitas dari informasi dan transparansi dengan melakukan pengungkapan tata kelola perusahaan sebaik mungkin (Baydoun dkk., 1999).

\section{Dewan Pengawas Syariah}

Dewan pengawas syariah memiliki peran penting dalam memastikan tata kelola syariah yang baik pada bank syariah (Abdullah Saif Alnasser dan Muhammed, 2012). Peran dewan pengawas syariah termasuk memberi nasihat kepada dewan direksi mengenai hal-hal terkait syariah untuk memastikan bahwa aktivitas bisnis perusahaan telah dijalankan sesuai dengan prinsip-prinsip syariah termasuk untuk produk dan layanan yang diberikan serta kebijakan internal (Hassan dan Christopher, 2005).

Farook dkk. (2011) menyatakan bahwa jumlah anggota dewan pengawas syariah yang besar dapat meningkatkan pengungkapan informasi yang lebih tinggi karena kapasitas pemantauan aktivitas bisnis perusahaan semakin meningkat. Semakin besar jumlah anggota dalam dewan pengawas syariah, maka semakin besar jumlah pemantauan yang menyiratkan tingkat kepatuhan lebih besar terhadap hukum dan prinsip-prinsip Islam (Farook dkk., 2011). Dewan pengawas syariah yang lebih besar dapat mengalokasikan fungsinya di seluruh kelompok anggota sehingga memungkinkan dewan pengawas syariah untuk meninjau lebih banyak aspek kegiatan bank dan memastikan kepatuhan yang lebih besar, termasuk dalam aspek tata kelola perusahaan (Abdullah dkk., 2015).

\section{KERANGKA KONSEPTUAL/METODO-LOGI PENELITIAN}

Penelitian ini memiliki tujuan untuk menguji pengaruh ukuran bank syariah, jumlah dewan direksi Muslim, serta proporsi dewan pengawas syariah terhadap luas pengungkapan tata kelola perusahaan pada bank syariah di Indonesia.

Jumlah aset yang besar menimbulkan risiko yang semakin besar pula pada proses pengendalian yang harus dijalankan perusahaan sehingga dapat menimbulkan bias informasi (Buzby, 1975). Oleh karena itu, untuk memberikan kepercayaan kepada para pihak berkepentingan terkait proses pengendalian yang dimiliki oleh bank syariah, maka manajemen bank syariah berusaha untuk mengungkapkan tata kelola perusahaan secara lebih luas (Abdullah dkk., 2015). Hal ini dimaksudkan untuk memberikan bukti seberapa baik manajemen dalam mengelola besar aset yang dimiliki untuk memberikan keuntungan kepada para pemegang saham bank syariah (Abdullah dkk., 2015). Semakin besar aset yang dimiliki oleh bank syariah dapat memberikan kemudahan untuk manajemen bank syariah dalam menjalankan tata kelola perusahaan secara lebih baik (Farook dkk., 2011).

Hasil dari penelitian oleh Abdullah dkk. (2015); Buzby (1975); Hamid (2004); memberikan bukti bahwa ukuran bank syariah berpengaruh positif terhadap pengungkapan tata kelola perusahaan. Abdullah dkk. (2015); Buzby (1975); \& Hamid (2004) mengungkapkan bahwa bank syariah dengan ukuran yang lebih besar pada umumnya memiliki sumber daya yang lebih baik untuk tata kelola perusahaan mereka.

$\mathrm{H}_{1}$ : Ukuran bank syariah berpengaruh positif terhadap luas pengungkapan tata kelola perusahaan pada bank syariah. 
Albassam dan Ntim (2017) menyatakan bahwa dewan direksi Muslim dalam jajaran dewan direksi bank syariah dapat memberi tekanan kepada bank syariah untuk lebih dalam melakukan proses internalisasi nilai-nilai Islam dan meningkatkan transparansi perusahaan. Lebih lanjut Albassam dan Ntim (2017) mengungkapkan bahwa banyaknya dewan direksi Muslim dalam bank syariah dapat memberi masukan kepada manajemen untuk meningkatkan pengungkapan tata kelola perusahaannya.

Hasil dari penelitian Baydoun dkk. (1999); Allegrini dan Greco (2013) memberikan bukti bahwa dewan direksi Muslim memiliki pengaruh positif terhadap luas pengungkapan tata kelola perusahaan. Baydoun dkk. (1999); Allegrini dan Greco (2013) mengungkapkan bahwa bank syariah yang memiliki jumlah dewan direksi Muslim lebih besar memiliki perilaku yang lebih baik dalam menjaga agar nilai-nilai Islam senantiasa menjadi panutan bagi bank syariah. Lebih lanjut, Baydoun dkk. (1999); Allegrini dan Greco (2013) menyatakan dewan direksi Muslim lebih menyakini nilai-nilai Islam untuk diterapkan dalam aktivitas bisnis yang dijalankan, sehingga dapat memberi dorongan untuk lebih transparan terkait aktivitas bisnisnya dengan melakukan pengungkapan tata kelola perusahaan dengan sebaik mungkin.

H2: Proporsi dewan direksi Muslim berpengaruh positif terhadap luas pengungkapan tata kelola perusahaan pada bank syariah.

Dewan pengawas syariah memiliki tanggung jawab yang penting dalam bank syariah sebagai pihak yang dapat mengotorisasi atau menyetujui berbagai transaksi maupun kegiatan yang dilakukan oleh bank syariah, selain itu dewan pengawas syariah juga bertindak untuk memonitor jajaran direksi dalam menjalankan aktivitas bisnisnya supaya tetap dalam koridor prinsip syariah (Mohammed dkk., 2017). Abdullah dkk. (2015) mengungkapkan bahwa semakin besar jumlah anggota dewan pengawas syariah dapat memberikan desakan kepada manajemen bank syariah supaya menerapkan nilai-nilai Islam dalam setiap kegiatan operasional perusahaan untuk menyesuaikan dengan prinsip syariah yang berlaku termasuk meningkatkan transparansi, sehingga dapat mendorong manajemen bank syariah untuk memberikan pengungkapan tata kelola perusahaan lebih baik (Mohammed dkk., 2017).

Hasil dari penelitian oleh Farook dkk. (2011) \& Raman dan Bukair (2013) memberikan bukti bahwa dewan pengawas syariah memiliki pengaruh positif terhadap pengungkapan tata kelola perusahaan. Farook dkk. (2011) \& Raman dan Bukair (2013) menyatakan bahwa bank syariah yang memiliki jumlah dewan pengawas syariah relatif besar dapat melakukan pengawasan dan pemantauan yang lebih efektif, sehingga menghasilkan tingkat pengungkapan informasi dan tata kelola perusahaan yang lebih tinggi.

H3: Proporsi dewan direksi Muslim berpengaruh positif terhadap luas pengungkapan tata kelola perusahaan pada bank syariah.

Penyajikan model penelitian ini dapat dilihat pada gambar sebagai berikut.

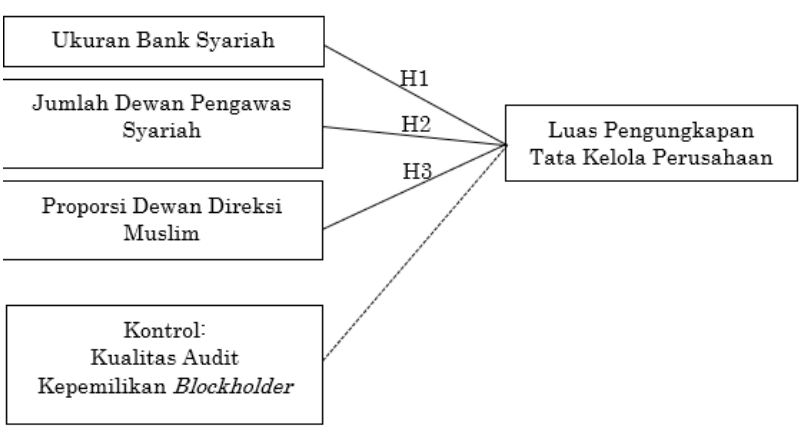

Penelitian ini menggunakan data yang diperoleh dari laporan tahunan dan laporan tata kelola perusahaan bank syariah yang terdaftar 
di Indonesia periode 2015-2018. Prosedur penentuan sampel dilakukan secara purposive sampling. Sebanyak 41 data sampel perusahaan yang memenuhi kriteria pemilihan dan dapat diobservasi dalam penelitian.

\section{Definisi Operasional dan Pengukuran Variabel}

\section{Variabel Dependen}

Luas pengungkapan tata kelola perusahaan diukur menggunakan Indeks tata kelola perusahaan (Albassam, 2014). Indeks tata kelola perusahaan memiliki empat dimensi, (1) dewan perusahaan, (2) pengungkapan dan transparansi, (3) pengendalian internal dan manajemen risiko, serta (4) pemegang saham dan majelis umum. Proksi dewan direktur dan dewan sub-komite, pengungkapan dan transparansi, pengendalian internal dan manajemen risiko, serta pemegang saham dan majelis umum merupakan sub indeks dari corporate governance index. Item dari masing-masing ketentuan dapat diukur dengan menggunakan content analysis dengan nilai 1 jika diungkapkan dan 0 jika sebaliknya.

Luas pengungkapan corporate governance dinilai berdasarkan indeks pengungkapan yang dikembangkan berdasarkan jumlah tolok ukur tata kelola perusahaan (Albassam dan Ntim, 2017), dihitung dengan persamaan sebagai berikut.

Indeks tata kelola perusahaan $=\frac{\text { Jumlah item yang diungkapkan }}{\text { Total item pengungkapan }}$

\section{Variabel Independen}

1. Ukuran bank syariah diukur berdasarkan logaritma natural total aset bank syariah sebagai berikut.

SIZE $=$ Ln (Total Aset)
2. Dewan direksi Muslim dihitung berdasarkan proporsi dari dewan direksi Muslim yang dirumuskan sebagai berikut.

Proporsi dewan direksi muslim $=\frac{\text { Dewan direksi muslim }}{\text { Total dewan direksi }}$

3. Dewan pengawas syariah dihitung berdasarkan jumlah dari dewan pengawas syariah pada bank syariah.

\section{Variabel Kontrol}

1. Kualitas audit bank syariah diukur dengan menggunakan variabel dummy dengan nilai 1 apabila bank syariah diaudit oleh KAP yang terafiliasi dengan Big Four dan nilai 0 untuk sebaliknya.

2. Kepemilikan block holder bank syariah diukur dengan menggunakan variabel dummy dengan nilai 1 jika pada bank syariah terdapat kepemilikan block holder dan nilai 0 jika sebaliknya.

Teknik analisis yang digunakan adalah uji regresi linier berganda. Uji regresi linier berganda pada penelitian ini dilakukan dengan menggunakan program SPSS 25.0. Model regresi yang digunakan untuk menguji hipotesis dirumuskan sebagai berikut.

$\mathrm{Y}_{\mathrm{it}}=\alpha+\beta_{1} \mathrm{X} 1_{\mathrm{it}}+\beta_{2} \mathrm{X} 2_{\mathrm{it}}+\beta_{3} \mathrm{X} 3_{\mathrm{it}}+\beta_{4} \mathrm{X} 4_{\mathrm{it}}+\beta_{5} \mathrm{X} 5_{\mathrm{it}}+\varepsilon_{\mathrm{it}} \ldots$. (1)

Keterangan:

: Konstanta

: Koefisien regresi

$\mathrm{Y}$ : Luas pengungkapan tata kelola perusahaan

$\mathrm{X}_{1}$ : Ukuran bank syariah

$\mathrm{X}_{2}$ : Proporsi dewan direksi Muslim

$\mathrm{X}_{3}$ : Jumlah dewan pengawas syariah

$\mathrm{X}_{4}$ : Kualitas audit

$\mathrm{X}_{5}$ : Kepemilikan block-holder

it : Error perusahaan $i$ tahun $t$ 


\section{HASIL DAN DISKUSI}

\section{Analisis Deskriptif}

Analisis deskriptif digunakan untuk memberikan informasi dan gambaran umum mengenai data variabel-variabel yang digunakan dalam penelitian, yaitu variabel luas pengungkapan corporate governance (CGI), ukuran bank syariah (UP), proporsi dewan direksi Muslim (PPDM), jumlah dewan pengawas syariah (JDPS), kualitas audit (AQ), block-holder ownership (BO), pembayaran dividen (DIV), dan leverage (LEV). Analisis deskriptif mengungkapkan informasi mengenai standar deviasi, mean, nilai minimum dan nilai maksimum untuk masing-masing variabel yang digunakan. Analisis deskriptif variabel yang digunakan dalam penelitian disajikan pada Tabel 1.

\begin{tabular}{|c|l|r|r|r|r|}
\hline & N & Minimum & Maximum & Mean & $\begin{array}{c}\text { Std. } \\
\text { Deviation }\end{array}$ \\
\hline $\mathrm{Y}$ & 41 & 0.688 & 0.875 & 0.7919 & 0.0490 \\
$\mathrm{X}_{1}$ & 41 & 27.920 & 32.108 & 30.0147 & 1.3899 \\
$\mathrm{X}_{2}$ & 41 & 0.500 & 1.000 & 0.8525 & 0.1429 \\
$\mathrm{X}_{3}$ & 41 & 2 & 3 & 2.24 & 0.538 \\
$\mathrm{X}_{4}$ & 41 & 0 & 1 & 0.49 & 0.506 \\
$\mathrm{X}_{5}$ & 41 & 0 & 1 & 0.93 & 0.264 \\
Valid N & 41 & & & & \\
(listwise) & & & & \\
\hline
\end{tabular}

Pada Tabel 1 tersebut luas pengungkapan tata kelola perusahaan $(\mathrm{Y})$ memiliki nilai terendah 0,688 dan tertinggi 0,875. Berdasarkan data, nilai terendah indeks pengungkapan tata kelola perusahaan dimiliki oleh Bank Jabar Banten Syariah pada tahun 2015 dan nilai terbesar indeks pengungkapan tata kelola perusahaan dimiliki oleh Bank Panin Syariah pada tahun 2018. Rata-rata indeks pengungkapan tata kelola perusahaan yang dimiliki seluruh perusahaan sampel adalah 0,7919 dengan standard deviasi 0,0490. Hal ini memperlihatkan bahwa tingkat sebaran data indeks pengungkapan tata kelola perusahaan mempunyai tingkat variasi $6,1876 \%$. Dapat disimpulkan bahwa indeks pengungkapan tata kelola perusahaan pada perusahaan sampel relatif seragam. Artinya, luas pengungkapan tata kelola perusahaan sample dalam penelitian ini relatif sama. Kondisi ini mengisyaratkan bahwa bank syariah yang menjadi sampel penelitian memiliki penerapan kebijakan tata kelola yang cenderung sama.

Ukuran bank syariah $\left(\mathrm{X}_{1}\right)$ mempunyai nilai terendah 27,920 dan tertinggi 32,108. Berdasarkan data, nilai terendah ukuran bank syariah dimiliki oleh PT Bank Maybank Syariah Indonesia tahun 2017 dan nilai terbesar ukuran bank syariah dimiliki oleh PT Bank Syariah Mandiri tahun 2018. Rata-rata ukuran bank syariah pada seluruh perusahaan sampel adalah 30,0147 dengan standard deviasi 1,3899. Hal ini memperlihatkan bahwa tingkat sebaran data ukuran bank syariah mempunyai tingkat variasi 4,6307\%. Dapat disimpulkan bahwa ukuran bank syariah pada perusahaan sampel relatif seragam. Kondisi ini mengisyaratkan bahwa besar aset yang dimiliki bank syariah pada sampel penelitian relatif sama, artinya bank syariah memiliki nilai aset yang digunakan untuk kegiatan operasionalnya relatif sama.

Proporsi dewan direksi Muslim $\left(\mathrm{X}_{2}\right)$ mempunyai nilai terendah 0,5 dan tertinggi 1 . Berdasarkan data, nilai terendah proporsi dewan direksi Muslim dimiliki oleh PT Bank BCA Syariah tahun 2015, 2016, 2017, dan 2018 sedangkan nilai tertinggi proporsi dewan direksi Muslim dimiliki oleh empat perusahaan di tahun 2015, empat perusahaan di tahun 2016, empat perusahaan di tahun 2017, tiga perusahaan di tahun 2018. Rata-rata proporsi dewan direksi Muslim perusahaan sampel adalah 0,8525 dengan standar deviasi 0,1429. Hal ini memperlihatkan tingkat sebaran data dari proporsi dewan direksi Muslim memiliki tingkat variasi sebesar 16,7624\%. Dapat disimpulkan bahwa proporsi dewan direksi Muslim perusahaan sampel relatif 
seragam. Artinya, perusahaan sampel memiliki komposisi atau jumlah dewan direksi Muslim yang relatif sama. Kondisi ini mengisyaratkan kebijakan bank syariah dalam menetapkan dewan direksinya didominasi oleh dewan direksi yang memeluk agama Islam.

Jumlah dewan pengawas syariah $\left(\mathrm{X}_{3}\right)$ mempunyai nilai terendah 2 dan tertinggi sebesar 3 . Berdasarkan data, nilai terendah jumlah dewan pengawas syariah dimiliki oleh tujuh perusahaan di tahun 2015, tujuh perusahaan di tahun 2016, tujuh perusahaan di tahun 2017, enam perusahaan di tahun 2018. Sedangkan, jumlah tertinggi dewan pengawas syariah dimiliki oleh tiga perusahaan di tahun 2015, empat perusahaan di tahun 2016, empat perusahaan di tahun 2017 dan tiga perusahaan di tahun 2017. Rata-rata jumlah dewan pengawas syariah perusahaan sampel adalah 2,24 dengan standar deviasi 0,538. Hal ini memperlihatkan bahwa tingkat sebaran data jumlah dewan pengawas syariah memiliki tingkat variasi sebesar 24,0179\%. Dapat disimpulkan bahwa jumlah dewan pengawas syariah pada perusahaan sampel relatif rendah. Kondisi ini mengisyaratkan bahwa perusahaan sampel mempunyai jumlah dewan pengawas syariah yang cenderung sama. Artinya, kebijakan bank syariah dalam menentukan jumlah dewan pengawas syariah lebih kepada memenuhi syarat yang ditetapkan terkait jumlah minimum dewan pengawas syariah, yakni sebanyak dua dewan pengawas syariah.

Kualitas audit (X4) memiliki nilai minimum 0 dan nilai maksimum 1 . Nilai 0 dan 1 pada kualitas audit ini adalah nilai dari variabel dummy. Nilai 1 digunakan untuk menyatakan bank syariah yang diaudit oleh KAP yang terafiliasi dengan The Big Four, dan nilai 0 digunakan untuk menyatakan bank syariah yang tidak diaudit oleh KAP yang terafiliasi dengan The Big Four. Rata-rata kualitas audit yang dimiliki perusahaan sampel adalah 0,49 dengan standar deviasi 0,506. Tingkat sebaran data kualitas audit mempunyai tingkat variasi $103,265 \%$. Kondisi ini mengisyaratkan bahwa kualitas audit bank syariah pada penelitian ini relatif sama. Artinya, sebagian besar bank syariah memiliki kebijakan pemilihan auditor untuk mengaudit laporan keuangan yang cenderung serupa, yakni menggunakan jasa auditor yang terafiliasi dengan The Big Four.

Kepemilikan mayoritas perusahaan (X5) memiliki nilai minimum 0 dan nilai maksimum 1. Nilai 0 dan 1 pada kepemilikan mayoritas perusahaan adalah variabel dummy. Nilai 1 digunakan apabila pada bank syariah terdapat kepemilikan mayoritas sedangkan nilai 0 digunakan apabila pada bank syariah tidak terdapat kepemilikan mayoritas. Rata-rata persentase kepemilikan mayoritas pada sampel adalah 0,93 dengan standar deviasi 0,264. Dapat disimpulkan tingkat sebaran data persentase kepemilikan mayoritas mempunyai tingkat variasi sebesar 28,3871\%. Artinya, kepemilikan mayoritas pada bank syariah dalam penelitian ini relatif sama. Pada bank syariah di wilayah Indonesia masih didominasi oleh kepemilikan mayoritas.

\section{Analisis Model dan Pembuktian Hipotesis}

Penelitian ini diuji dengan menggunakan analisis regresi linier berganda. Hasil dari analisis regresi linier berganda dapat dilihat pada Tabel 2 berikut.

\begin{tabular}{|l|r|r|c|r|r|}
\hline \multirow{2}{*}{ Model } & \multicolumn{2}{|c|}{$\begin{array}{c}\text { Unstandardized } \\
\text { Coefficients }\end{array}$} & $\begin{array}{c}\text { Standardized } \\
\text { Coefficients }\end{array}$ & \multirow{2}{*}{$\mathbf{t}$} & \multirow{2}{*}{ Sig. } \\
\cline { 2 - 4 } & B & \multicolumn{1}{|c|}{$\begin{array}{c}\text { Std. } \\
\text { Error }\end{array}$} & Beta & & \\
\hline (Constant) & 0.191 & 0.164 & & 1.170 & 0.250 \\
X1 & 0.014 & 0.006 & 0.394 & 2.524 & 0.016 \\
X2 & 0.107 & 0.043 & 0.313 & 2.515 & 0.017 \\
1 X3 & 0.033 & 0.013 & 0.360 & 2.500 & 0.017 \\
X4 & -0.018 & 0.013 & -0.181 & -1.326 & 0.193 \\
X5 & 0.029 & 0.026 & 0.157 & 1.129 & 0.267 \\
\hline
\end{tabular}


Hipotesis 1 menyatakan bahwa ukuran bank syariah berpengaruh positif dan signifikan terhadap luas pengungkapan tata kelola perusahaan. Dapat dilihat dari nilai koefisien regresi ukuran bank syariah $\left(\mathrm{X}_{1}\right)$ adalah 0,014 dan nilai signifikansi ukuran bank syariah $\left(\mathrm{X}_{1}\right)$ sebesar 0,016 di mana tingkat signifikansi yang dihitung $<$ dari tingkat kepercayaan 0,05 . Hal ini mengindikasikan bahwa semakin besar ukuran bank syariah akan meningkatkan luas pengungkapan tata kelola perusahaan dari bank syariah.

Hipotesis 2 menyatakan proporsi dewan direksi Muslim berpengaruh positif dan signifikan terhadap luas pengungkapan tata kelola perusahaan. Dapat dilihat dari nilai koefisien regresi proporsi dewan direksi Muslim $\left(\mathrm{X}_{2}\right)$ adalah 0,107 dan nilai signifikansi proporsi dewan direksi Muslim $\left(\mathrm{X}_{2}\right)$ sebesar 0,017 di mana tingkat signifikansi yang dihitung $<$ dari taraf kepercayaan 0,05 . Hal ini mengindikasikan bahwa keberadaan dewan direksi Muslim dalam struktur organisasi bank syariah mampu memberikan pengaruh yang signifikan dalam mendorong penghayatan nilai-nilai Islam dalam kegiatan operasional bank syariah sehingga meningkatkan transparansi bank syariah melalui pengungkapan tata kelola perusahaan yang baik.

Hipotesis 3 menyatakan dewan pengawas syariah berpengaruh positif terhadap luas pengungkapan tata kelola perusahaan. Dapat dilihat berdasarkan koefisien regresi jumlah dewan pengawas syariah (X3) yakni 0,033 dan nilai signifikansi jumlah dewan pengawas syariah (X3) sebesar 0,017 di mana tingkat signifikansi yang dihitung $<$ dari tingkat kepercayaan 0,05. Hal ini mengindikasikan bahwa semakin besar jumlah dewan pengawas syariah dalam struktur organisasi bank syariah mampu memberikan pengaruh signifikan terkait peningkatan luas pengungkapan tata kelola perusahaan.

\section{KESIMPULAN}

Tujuan dari penelitian ini adalah untuk mengetahui seberapa luas pengungkapan tata kelola perusahaan yang dilakukan oleh bank syariah dipengaruhi oleh ukuran bank syariah, banyaknya dewan direksi Muslim, serta adanya dewan pengawas syariah. Hasil pengujian dan analisis yang dilakukan dalam penelitian ini membuktikan bahwa ukuran bank syariah berpengaruh positif dan signifikan terhadap luas pengungkapan tata kelola perusahaan bank syariah. semakin besar ukuran bank syariah yang diukur dari total aset yang dimiliki bank syariah dapat meningkatkan luas pengungkapan tata kelola perusahaan bank syariah. Dalam hal ini jumlah aset yang besar dapat menunjukkan seberapa baik kemampuan bank syariah dalam mengelola dananya untuk memfasilitasi manajemen bank syariah dalam melaksanakan tata kelola perusahaan yang efektif dan memadai, sehingga bank syariah dapat mengungkapkan informasi kepada pihak berkepentingan dengan lebih lengkap dan lebih transparan.

Hasil pengujian dan analisis yang dilakukan dalam penelitian memberikan bukti bahwa banyaknya dewan direksi Muslim berpengaruh positif dan signifikan terhadap luas pengungkapan tata kelola perusahaan. Keberadaan jajaran dewan direksi yang beragama Islam dalam struktur organisasi perusahaan mampu memberikan dampak yang dalam memotivasi bank syariah untuk lebih aktif dalam mengungkapkan informasi melalui pengungkapan tata kelola perusahaan yang baik kepada publik sebagai bentuk transparansi yang menjadi bagian dari tanggung jawab manajemen.

Hasil pengujian dan analisis yang dilakukan dalam penelitian memberikan bukti bahwa dewan pengawas syariah berpengaruh positif dan signifikan terhadap luas pengungkapan tata kelo- 
la perusahaan. Keberadaan dewan pengawas syariah dalam struktur organisasi perusahaan mampu memberikan pengaruh yang signifikan terhadap peningkatan luas pengungkapan tata kelola perusahaan. Semakin banyak jumlah dewan pengawas syariah mampu meningkatkan proses pengawasan dan pemantauan pada manajemen perusahaan dalam mengimplementasikan prinsip-prinsip syariah yang salah satunya adalah meningkatkan transparansi terkait informasi dalam setiap kegiatan operasional perusahaan yang disajikan dalam pengungkapan tata kelola perusahaan.

\section{DAFTAR PUSTAKA}

Abdullah Saif Alnasser, S., \& Muhammed, J. 2012. Introduction to Corporate Governance from Islamic Perspective. Humanomics, 28(3), 220-231.

Abdullah, W.A.W., Percy, M., \& Stewart, J. 2015. Determinants of Voluntary Corporate Governance Disclosure: Evidence from Islamic Banks in the Southeast Asian and the Gulf Cooperation Council regions. Journal of Contemporary Accounting Economics, 11(3), 262-279.

Adams, C.A. 2002. Internal Organisational Factors Influencing Corporate Social and Ethical Reporting: Beyond Current Theorising. Accounting, Auditing \& Accountability Journal, 15(2), 223-250.

Albassam, W.M. \& Ntim, C.G. 2017. The Effect of Islamic Values on Voluntary Corporate Governance Disclosure: The Case of Saudi-listed firms. Journal of Islamic Accounting Business Research, 8(2), 182202.

Allegrini, M. \& Greco, G. 2013. Corporate Boards, Audit Committees and Voluntary
Disclosure: Evidence from Italian Listed Companies. Journal of Management $\sigma$ Governance, 17(1), 187-216.

Archer, S., Ahmed Abdel Karim, R., \& Sundararajan, V. 2010. Supervisory, Regulatory, and Capital Adequacy Implications of Profit-Sharing Investment Accounts in Islamic Finance. Journal of Islamic Accounting and Business Research, 1(1), 10-31.

Baydoun, N., Mamman, A., \& Mahmaud, A. 1999. The Religious Context of Management Practices: The Case of the Islamic Religion, Accounting, Commerce \& Finance. The Islamic Perspective Journal, 3(1/2), 52-79.

Beekun, R. \& Badawi, J. 1999. The Leadership Process in Islam. PROTEUS-SHIPPENSBURG-, 16, 33-38.

Botosan, C.A. 1997. Disclosure Level and the Cost of Equity Capital. Accounting Review, 323-349.

Buzby, S.L. 1975. Company Size, Listed Versus Unlisted Stocks, and the Extent of Financial Disclosure. Journal of Accounting Research, 16-37.

Fama, E.F. \& Jensen, M.C. 1983. Separation of Ownership and Control. The Journal of Law and Economics, 26(2), 301-325.

Farook, S., Kabir Hassan, M., \& Lanis, R. 2011. Determinants of Corporate Social Responsibility Disclosure: The Case of Islamic Banks. Journal of Islamic Accounting Business Research, 2(2), 114-141.

Hamid, F.Z.A. 2004. Corporate Social Disclosure by Banks and Finance Companies: Malaysian Evidence. Corporate Ownership and Control, 1(4), 118-130.

Haniffa, R. \& Hudaib, M. 2006. Corporate Governance Structure and Performance of Malaysian Listed Companies. Journal 
of Business Finance \& Accounting Analysis, 33(7-8), 1034-1062.

Hassan, S., \& Christopher, T. 2005. Corporate Governance Statement Disclosure of Malaysian Banks and The Role of Islam. Asian Review of Accounting, 13(2), 3650.

Jensen, M.C. \& Meckling W.H. 1976. Theory of the Firm: Managerial Behavior, Agency Costs and Ownership Structure. Journal of Financial Economics, 3(4), 305-360.

Mohammed, A.N., Saif, S.A., \& Muhammed, J. 2017. The Relationship between Agency Theory, Stakeholder Theory and Shariah Supervisory Board in Islamic Banking: An Attempt Towards Discussion. Humanomics, 33(1), 75-83.

O'Sullivan, M. 2005. An Investigation of the Role Played by Corporate Governance in the Voluntary Disclosure of Forward-Looking Information and The Quality of Corporate Financial Reports. Queensland University of Technology, Brisbane.
Raman, A.A. \& Bukair, A.A. 2013. The Influence of the Shariah Supervision Board on Corporate Social Responsibility Disclosure by Islamic Banks of Gulf Co-operation Council Countries. Asian Journal of Business and Accounting, 6(2).

Safieddine, A. 2009. Islamic Financial Institutions and Corporate Governance: New Insights for Agency Theory. Corporate Governance: An International Review, 17(2), 142-158.

Sarker, M.A.A. 1999. Islamic Business Contracts, Agency Problem and the Theory of the Islamic Firm. International Journal of Islamic Financial Services, 1(2), 12-28.

Solomon, J.F. \& Solomon, A. 2006. Private Social, Ethical and Environmental Disclosure. Accounting, Auditing \& Accountability Journal, 19(4), 564-591.

Vinnicombe, T. 2010. AAOIFI Reporting Standards: Measuring Compliance. Advances in Accounting, 26(1), 55-65. 